\title{
Practical Guidance for Developing State-and-Transition Models
}

\section{By Brandon T. Bestelmeyer, Kendra Moseley, Pat L. Shaver, Homer Sanchez, David D. Briske, and Maria E. Fernandez- Gimenez}

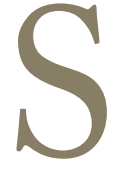
tate-and-transition models (STMs) are synthetic descriptions of the dynamics of the vegetation and surface soils occurring within specific ecological sites. ${ }^{1}$ STMs consist of a diagram and narratives that describe these dynamics and evidence for the causes. ${ }^{1}$ STMs are developed using a broad array of evidence including historical information, local and professional knowledge, general ecological knowledge, and monitoring and experimental data from a specific ecological site or similar sites.

STMs are used to develop and apply adaptive management strategies. ${ }^{2,3}$ Specifically, ecological sites and STMs should be designed to assist land managers with the following tasks:

1) stratify the landscape according to varying ecological potential in order to identify management and restoration targets,

2) assess the risk of degradation and take proactive measures to avoid it,

3) specify constraints to, and opportunities for, desirable transitions based on a knowledge of ecological processes,

4) identify specific intervention strategies that can promote desirable transitions, and

5) design and interpret monitoring based on interventions and expected responses.

With these functions in mind, we provide general guidance on the production of rangeland STMs with special attention to recent concepts. We describe the preparation and a sequence of steps in the development of STMs that parallels the steps in ecological site development discussed by Moseley et al. (this issue). STMs are usually developed alongside ecological site concepts because STMs help to define differences among sites. We follow the steps with a discussion of common problems encountered by model developers and provide advice for how to resolve them. We then conclude with forward-looking ideas that bear upon the present-day development of STMs.

\section{Preparing to Develop a Set of STMs}

It is useful to begin new model development by using published research to develop one or more general models ${ }^{4}$ describing the ecological dynamics of management concern at the level of Major Land Resource Areas (MLRA) or broader climatic regions. For example, in the Chihuahuan Desert of southern New Mexico and west Texas (coded MLRA 42 by the USDA Natural Resource Conservation Service), the primary changes of management concern involve the loss of perennial grasses and their replacement by shrubs. A large body of scientific research describes this process worldwide. The primary question then becomes how the processes in the general models are conditioned or modified by ecological sites in a landscape to produce distinct STMs (Fig 1). Each ecological site features a distinct reference state and variations on the alternative states and transition/restoration processes compared to the general models. Model developers should consider the general questions summarized in Table 1, particularly in a workshop setting.

\section{Steps in Developing a Set of STMs}

Information from published research, interviews, and field inventory data (see Moseley et al., this issue) is used to develop the diagram and narratives for each component of the STM for each ecological site. We provide an example STM diagram in Figure 2 and an abbreviated example of the narratives and data for each component in Box 1. This model illustrates the primary components of an STM and indicates how the graphical and narrative portions relate to one another. Below, we describe a suggested sequence of six steps for developing an STM with emphasis on the narrative portions of each component (bolded in the text below) and 


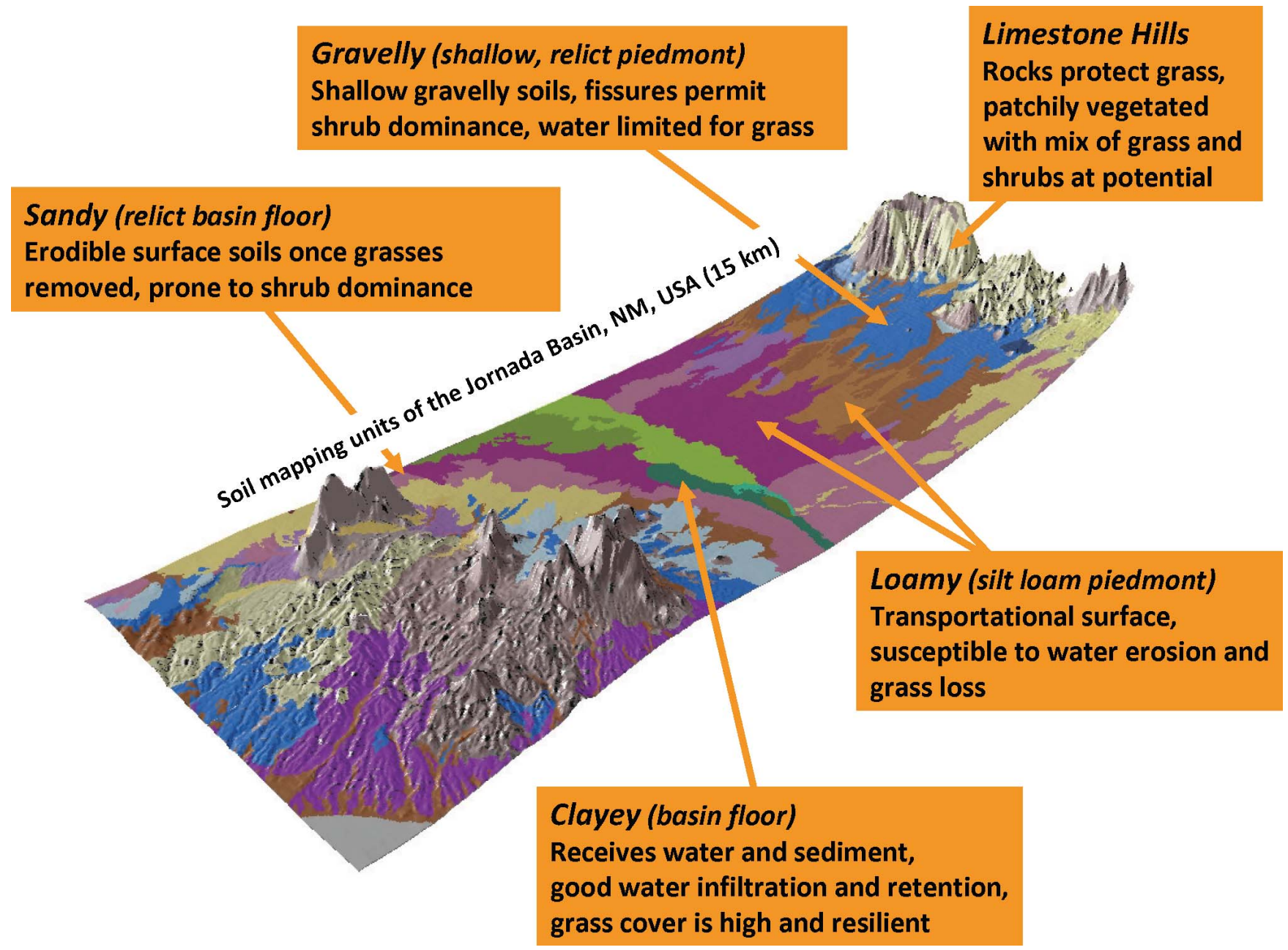

Figure 1. Soil map units of part of the southern Jornada Basin, New Mexico, USA, identifying ecological sites and key state-transition processes for the sites.

specify the kinds of evidence (i.e., data or local/expert knowledge) used to develop each component. Rather than offer formal definitions (a pending task of the interagency ecological site development effort in the United States), our goal here is to provide descriptions of components that may assist model developers in grasping their purposes within the overall STM framework. We refer readers to a series of recent papers for more detailed treatments of concepts, definitions, and approaches..$^{5-9}$

\section{Step 1: Define Community Phases}

Model development involving inventory data sets typically starts by identifying the various community phases associated with an ecological site concept. Community phases are the distinctive plant communities and associated dynamic soil property values ${ }^{10}$ that can occur over time within a state. Plant communities can be defined following varying rationales, but typically they reflect management-relevant differences in plant communities and focus on differences in dominant species that govern the ecological processes and uses of a site. Community phases might also be recognized based on habitat distinctions important to key animal species (e.g., shrub height).

For each proposed ecological site, inventory data of existing plant communities are usually coupled to local knowledge to define community phases. Multivariate analysis together with informed judgment can help to quantify distinct phases when based on persistent plant species. Historical records are consulted to estimate properties of phases that are no longer observed. Phases best approximating ecological potential (e.g., the reference community phase, see below) may be rare and specifically targeted for sampling (e.g., relict vegetation in cemeteries or exclosures).

\section{Step 2: Define States}

Concepts for states are developed that sort plant community phases according to the structures (e.g., dominant species, functional groups, and surface soil conditions) that control feedback mechanisms and ecological processes. The feedback mechanisms involve interactions between vegetation and/or soil conditions and processes that reinforce those conditions. One example is a state characterized by the 
Table 1. A sequence of questions to ask when developing ecological sites and state-and-transition models

What are the different possible ecological sites?

Are the soils sufficiently different in their potential plant communities?

Do the soils differ in the dynamics of plant communities or management needs?

Within an ecological site, what are the observed alternative communities?

What is the reference community phase?

What are other phases that should be recognized?

How should phases be grouped to alternative states based on ecological processes?

What are the slow variables, triggers, and thresholds associated with transitions?

What management interventions can prevent undesirable transitions?

How can desirable states be restored?

presence of grasses that supports fire that, in turn, prevents competitive displacement of the grasses by shrubs. States are thus distinguished according to structures (dominance of the perennial grass functional group) alongside characteristic feedbacks (fire that limits shrub establishment) and related processes (a low rate of shrub seed production). A general, if not comprehensive, list of types of rangeland states is offered in Table 2.

In practice, the identity of a state can be defined by temporal relationships among community phases. If shifts from one phase to another occur without intensive management, or can occur under specific, but common, climatic conditions, then the community phases belong within the same state. If intensive management (i.e., accelerating practices) is required to push the system to the previous phase or another desirable phase, then those phases occur in different states. The common structures (e.g., dominant plant functional groups) and processes (e.g., soil erosion or fire) linking community phases are used to name and develop the narrative for the state (e.g., an eroding shrubland state). The narrative for states includes the following elements.

Step 2a. The reference state is identified to represent the historical or natural state for the site including its range of variation. Reference states have been identified according to varying criteria, but they most often designate the historical range of variation at the time of European settlement. It is often implicitly assumed that historically observed states are those that provide the maximum options for management and ecosystem services. This is because they were relatively unaltered by modern human extractive activities.

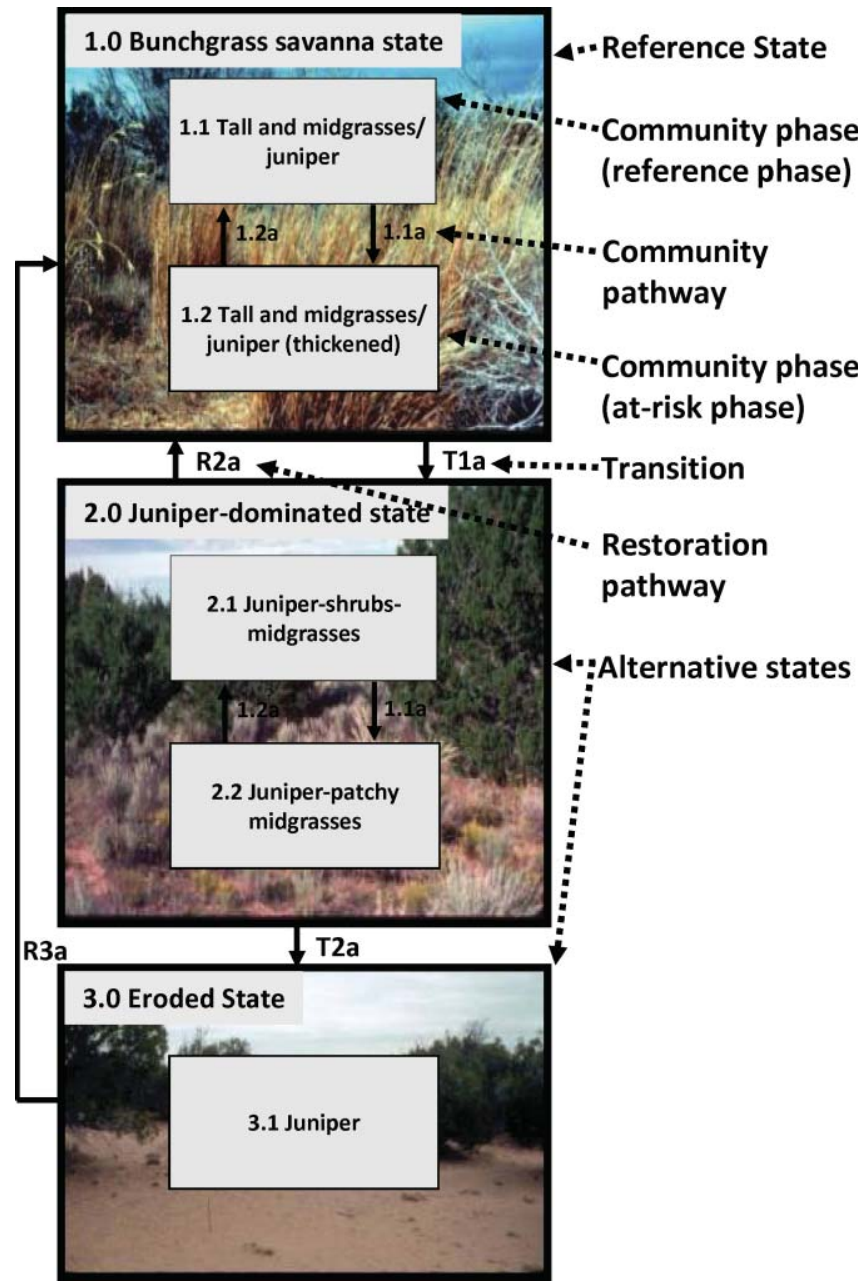

Figure 2. An example of a state-and-transition model (STM) for the Deep Sand Savannah ecological site, Major Land Resource Area 70C (Pecos-Canadian Plains and Valleys, New Mexico, USA). General parts of the STM are noted. The juniper is Juniperus monosperma (Engelm.) Sarg.

Within the reference state, the reference community phase is identified as that which best exhibits the characteristics of the reference state, or that is considered to be the most resilient within the state (i.e., a healthy condition vs. an at-risk condition, see below). In states featuring a natural or normal disturbance regime, this would be a phase that has not been disturbed recently, such as a late seral stage. This ensures that species typical of the state are observed and recorded. This phase is usually designated by the code 1.1 in an STM and is used as an ecological benchmark and to develop rangeland health reference sheets. ${ }^{11}$

The at-risk community phase is identified as the phase that is most vulnerable to a transition to an alternative state. Typically, this is defined for the reference state, but it should also be defined for other states. The description and data values for the "at-risk" phase should provide a clear distinction from the reference and other phases within the state. Phases can also be described in which the likelihood of restoration success is highest within the state, but this is best 
Box 1. Legend for the Deep Sand Savannah state-and-transition model in Figure 2. The text description is simplified; more detail can be added in complete models.

\subsection{Warm-season bunchgrass (reference state):}

Diagnosis and indicators: High perennial grass foliar cover $(>40 \%)$, tall grass foliar cover $>10 \%$. One-seed juniper foliar cover $<20 \%$ and trees $<4$ feet tall. Surface soil stability $>4$.

Feedbacks and ecological processes: Organic matter inputs and effects on soil structure allow for high seasonal soil water availability and herbaceous production. Grass-fueled fires prevent juniper dominance.

1.1 Warm-season tall and mid grasses (reference phase): Juniper foliar cover $<5 \%$, with most trees $<2$ feet. Canopy gaps $<8 \%$.

1.2 Warm-season mid and tall grasses with increasing juniper cover (at-risk phase): Juniper foliar cover 5-20\%, most trees $<4$ feet. Canopy gaps $>8 \%$ and fuels are adequate to carry fire.

Management: Maintain high herbaceous cover to promote organic matter inputs and facilitate fire frequencies that limit juniper establishment and growth (fire return interval of 10-15 years).

\section{Transition 1a}

Slow variables and triggers: Continuous year-long stocking that maintains perennial grass foliar cover below that needed to carry fire at least once every 10-15 years and that limits litter inputs for maintenance of soil organic matter levels.

Threshold: With lack of fire, junipers exceed 4 feet tall and fire mortality rates decline.

\subsection{Juniper-dominated state}

Diagnosis and indicators: Juniper foliar cover $>20 \%$ and height is generally $>4$ feet. Herbaceous foliar cover can be up to $45 \%$ but tall grass foliar cover is $<5 \%$. Surface soil stability $<3$.

Feedbacks and ecological processes: Junipers increasingly dominate use of soil water, resulting in decreasing herbaceous production and decreasing organic matter inputs, contributing to reductions in soil water availability to grasses and increased soil erodibility.

2.1 One-seed juniper-shrubs-warm-season mid grasses: Understory shrubs are common. Canopy gaps 7-15\% and basal cover $5-10 \%$.

2.2 One-seed juniper-patchy warm season mid grasses (at-risk phase): Understory shrubs are rare. Canopy gaps increasing $(15-30 \%)$ and basal cover reduced $(<4 \%)$. Increased soil erodibility.

Management: Grazing management to maintain understory shrub and herbaceous production and ground cover. When possible, prescribed burning or other brush management treatments are used to limit juniper and promote herbaceous cover.

\section{Restoration pathway R2a}

Juniper removal using herbicide or individual tree pushing/masticating coupled with reduced stocking rates to allow increased grass and litter production. If mechanical control is used, tractors should have rubber tires to minimize soil surface disturbance.

\section{Transition $2 a$}

Slow variables and triggers: Persistence and increases in juniper cover within this state cause a decrease in shrub understory and herbaceous cover and production. This leads to increasingly large bare gaps and reduced organic matter, which promote soil erosion.

Threshold: Low basal cover $(<4 \%)$ and extensive soil movement preclude natural reestablishment of herbaceous and shrub understory species.

\subsection{Eroded state}

Diagnosis and indicators: Juniper foliar cover $>30 \%$, herbaceous foliar cover usually $<10 \%$. Surface soil stability $<2.0$, canopy gaps $>30 \%$, basal cover $<4 \%$, and bare ground $>40 \%$. Common evidence of wind and water erosion.

Feedbacks and ecological processes: Junipers monopolize available soil water and extensive, connected bare ground areas facilitate soil erosion, both processes inhibit recovery of herbaceous and shrub understory species. Organic matter inputs reduced, accelerating decreases in soil surface stability and wind and water erosion.

Management: Forage is usually insufficient for grazing use; soil surface disturbance should be minimized.

Restoration pathway R3a: Juniper removal using herbicide and management to minimize soil surface disturbance. Herbaceous recovery may take several decades or longer.

iThe percentage of a line length with canopy gaps $>200 \mathrm{~cm}$. 
Table 2. General types of concepts for distinct states in state-and-transition models

Concept

O. Reference

1. Native reproduction is limited

2. Native competitors dominant, altered processes

3. Nonnative species dominant, altered processes

4. Hydrologically impaired

5. Local soil degradation

6. Landscape soil degradation
Example

Savanna state

Altered savanna state, former dominant is minor component

Shrub-dominated state; sod-bound state

Annual-grass-dominated state (high frequency of fire)

Gullied state

Shrubland state (truncated soil); abandoned cropland state

Mobile dune/shrublands state placed in the restoration pathways narrative (see below). A description of specific indicators for the at-risk phase can serve as early warning of an undesirable transition.

Step 2b. Alternative states that can occupy a site are then identified. Like the reference state, they may represent a group of community phases comprising the range of variation within the state or only a single phase may be defined. Alternative states feature a distinct set of feedbacks and processes compared to the reference state; technology and/ or rare, extreme natural events (e.g., a once-in-a-century extreme wet year) would be needed to restore the reference state. Alternative states can be extremely persistent due to strong feedbacks, such as when exotic species invade and alter fire regimes and soil nutrient cycling.

In some cases, changes in vegetation and process rates (such as erosion) may continue to occur within an alternative state after the initial state transition. In such cases, the alternative state may gradually change to a second alternative state without management intervention. For example, an initial state transition is caused by a reduction of fire frequencies in a savanna reference state such that trees reach a size beyond which they cannot be killed by fire (a tree-dominated state). The expanding population of trees over time within this state decreases soil water availability for herbaceous vegetation and gradually displaces it. Thus, without timely management to control trees, a second transition occurs to an eroding state with scant herbaceous vegetation (see transition $2 \mathrm{a}$ in Figure 2 and Box 1). A second alternative state is recognized here because the role of ecological processes (erosion) and management needs (tree removal vs. tree removal alongside soil stabilization) has changed abruptly in response to a gradual process. In previous efforts, the tree-dominated state of this example has been called a "transient state" although it can simply be regarded as an alternative state given that the relevant processes and rationale are described.

\section{Step 3. Narrative Description of Each State}

Narratives should include the following three components.

Diagnosis and indicators of states. These are the measurements and indicators used to distinguish one state from other states. They quantify or describe structures that relate closely to ecological processes characterizing the state. Typically, measurements of plant composition, cover, height, and measurements or descriptions of the soil surface are used (e.g., evidence of soil loss or reduced aggregate stability). Multiple attributes are usually needed to distinguish states.

Feedbacks and ecological processes. The relationships between structures and ecological or physical processes that create the dynamics within each state should be described. Examples include the relationship between plant cover and water infiltration, herbaceous cover and fire frequency or shrub establishment, or tree height and susceptibility to fire-caused mortality. The transition (see below) describes how a disturbance or change in land use precipitates a change in these relationships.

Management. This section describes the management practices that are used to sustain the state, maximize the ecosystem services received from the state, or prepare the state for a restoration action when climatic or other opportunities present themselves. Management usually focuses on the variables that control resilience of the state (such as long-term grazing management), rather than the triggers that are often difficult to control (such as a severe drought year). When well understood, management strategies should be described in sufficient detail or connected to specific guidelines to allow the design of on-the-ground actions.

Because states are ultimately used to predict ecological dynamics, state concepts and narratives are ideally based on monitoring data and management or restoration experiments (e.g., did unassisted succession lead to recovery over a certain timeframe?). More often, local knowledge of plant community responses to management are used to define changes that require intensive management interventions vs. natural drivers or low-intensity management. Descriptions should refer to a science-based understanding of ecological processes to the extent that information is available.

\section{Step 4. Community Pathway Narratives}

Community pathway narratives describe the mechanisms of change among community phases within the same state. Once community phases are grouped within states based on 
an understanding of shifts among phases, the specific causes of shifts among phases within a state can be described. The narrative should include references to climate, management, disturbance, or changes in resource levels. For example, shifts among California annual plant community phases are known to be a function of rainfall seasonality and residual dry matter. ${ }^{12}$ Community pathways are best described using monitoring or inventory data coupled to information about climate, management, or other conditions. Experimental data are especially useful to explain why changes occur. Local knowledge is useful to obtain information about the effects of unusual events and general responses to climatic variability.

\section{Step 5. Transition Narratives}

The transition narratives describe the mechanisms of change among states. In contrast to community pathways, transitions are due to changing feedbacks and processes that subsequently limit the recovery of the former state. Thus, the transition narrative should focus on how changes in structures, such as plant cover, lead to changes in ecological processes that then transform the system to the new state. In existing STMs, there has been a tendency to focus exclusively on the management elements involved in the transition (e.g., continuous heavy grazing, fire suppression, brush control) but not on the other processes that define the mechanism of transition. STMs should communicate the mechanisms in detail because they underpin our efforts to develop useful early warning indicators and indicators of restoration opportunities. We suggest that the following two elements be described in the narratives for each transition. ${ }^{8}$

Slow variables and triggers. These are multiple drivers and events that initiate a transition to an alternative state. There are two elements of this narrative that can be considered. First are the slow variables that increase or decrease a state's likelihood of transition. Slow variables reflect more gradual processes such as shrub recruitment rates, rates of change in water table depth associated with land use, or long-term decreases in grass density. Changes in slow variables usually produce the conditions that contribute to the occurrence of at-risk community phases. Second, the triggers are discrete events that precipitate a transition, such as a drought period that stresses perennial grasses, an intense rainfall event that produces highly erosive overland flow, or a wildfire. Often, transitions occur when triggers coincide with at-risk (or low-resilience) conditions, such as when drought occurs in chronically low-cover grassland communities.

Thresholds. Thresholds have been defined as a set of conditions (and a point in time) beyond which altered ecosystem structures and functions do not recover by themselves. Operationally, we define thresholds in STMs via descriptions of vegetation, soils, and related processes that separate states and that signal the need for specific restoration actions. Thresholds are the consequences of the slow variables and triggers described above. For example, the appearance of deep gullies that channel overland water flow and divert it away from vegetation represents a threshold that subsequently precludes recovery of the former state without restoration. The slow variable-long-term reduced grass cover-made this threshold likely and a large rainfall event triggered the transition. Similarly, the height beyond which trees are no longer killed by fire in a savanna represents a threshold. Descriptions of thresholds should include reference to both structures (e.g., gullies) and processes (e.g., overland flow and soil moisture availability) that determine plant and soil dynamics.

Transitions can sometimes be documented in monitoring data. Supporting evidence often comes from historical reconstructions using ground and aerial photography coupled to local knowledge of slow variables and triggers. Knowledge of the mechanisms of transition can be obtained from experiments. The mechanisms that they reveal may be sufficiently general to help explain transitions on multiple ecological sites when coupled with the relevant local information. There may also be competing explanations for transitions and evidence for each explanation can be offered in the narratives. The proof, of course, is in the success or failure of management interventions to preserve desired states.

\section{Step 6. Restoration Narratives}

Restoration pathways describe the technologies, events, and conditions within alternative states (including susceptible community phases) that can lead to recovery of the former state. For example, what is the rate of application of a specific herbicide needed to reduce the cover of an invasive species, and under what conditions is the recovery of native species most likely? Like the management narrative above, there should be sufficient detail in the protocol described so that its costs, benefits, and efficacy can be evaluated. Additional contextual details should be considered, such as when the successful application of technologies requires particular local conditions. Examples include overseeding during a high-rainfall period or using high-moisture microsites in range plantings.

Local knowledge coupled to reconstructions of past restoration effects (e.g., measuring treated vs. untreated areas or using a series of historical aerial photographs) are the most common forms of evidence when changes occur slowly. New restoration treatments should be applied with control/treatment pairs and some form of monitoring in order to test restoration protocols and obtain information to improve the procedure in subsequent applications. The importance of an accessible archive where in-depth analyses of restoration activities can be reviewed and used as a guide for future decision-making cannot be overstated.

\section{Common Problems Encountered in Model Development Directional Climate Change}

Directional changes in climate have been difficult to represent in STMs. Long-term climate change causes gradual 
continuous change in plant communities rather than a more cyclical "range of variation." Past and present climate change has been treated as a driver (e.g., slow variable) that causes transitions between states. But climate change could also be treated as a change in ecological potential, and therefore, contribute to the formation of a new ecological site (or MLRA or Land Resource Unit). For example, there is evidence of millennium-scale shifts between grassland and woodland ecological potential at sites in the southwestern United States. Important changes in climate may occur very rapidly in the coming decades. There is no broadly accepted solution to this problem, although it has been proposed that distinct "regimes" could be used to reflect distinct periods of differing regional climate, each of which features a different STM. ${ }^{13}$ The focus of the STM then becomes how management and other events cause state transitions within a particular climatic regime.

\section{Anthropogenic and Faunal Processes Within the Reference State}

There is evidence in many parts of North America (as elsewhere) that pre-European humans had significant impacts on ecological dynamics, such as the use of fire by Native Americans. Thus, the concept of a reference state need not imply that it is pristine. It can simply be considered as a benchmark from which to evaluate changes in ecosystems due to modern management practices. Native American activities can be considered as part of the reference state.

Similarly, there is increasing evidence that animal activities may have important impacts on the plant composition and dynamics of reference states (see Gilgert and Zack, this issue). Examples include the effects of apex predators such as wolves on plant herbivory or the effects of prairie dogs on grassland vegetation and soils. Because these processes are unknown or controversial, they are often overlooked in STMs. Archeologists, paleobiologists, and wildlife biologists can be important resources for developing STMs.

\section{The Scale of a State: Patch Dynamics and Landscape-Level Effects}

The description of community phases, states, and transitions should include a description of spatial scale when possible. In some cases, patch dynamics can be important within states, such that the different community phases simultaneously co-occur within a landscape in different patches (e.g., patches in different post-fire successional stages). This is common in fire-governed ecological sites and riparian ecological sites (Stringham et al., this issue). In such cases, the state of the ecological site may need to be recognized at a sufficiently broad scale and the community phases and their scales described as patches occurring within the state. In fact, the state may be recognized by the coverage of different patch types, as is common in LANDFIRE-based models.

Similarly, the properties of a state and the processes causing transitions may be due to spatial interactions with adjacent ecological sites and states. This is a common issue in riparian ecological sites where the riparian state is partly due to conditions in upslope ecological sites that produce water runoff to riparian areas. In such cases, state-and-transition narratives should refer to processes emerging from other ecological sites (and their states) and the landscape settings and spatial scales in which these processes act. For example, erosion in a draw ecological site is more likely to accelerate when adjacent gravelly sites occur on steeper slopes and have low grass cover.

\section{Suggestions to Increase the Utility of STMs Compare Dynamics Among Ecological Sites that Share an MLRA}

Currently, ecological site descriptions (ESDs) do not allow for comparisons of dynamics among ecological sites. For example, we might have evidence that Shallow-sandy ecological sites can maintain higher grass cover during drought and under similar management compared to Deep sand ecological sites. Such comparisons are not easy to discern in current ESDs. Following from the recommendation to start with broad, MLRA-level models, it would be useful to develop synthetic overviews comparing ecological site properties and STMs across the group of models produced for a Land Resource Unit or MLRA. Another way to accomplish this would be to include comparisons with similar ecological sites in the beginning narrative portion of STM text.

\section{Prepare STMs to be Revised}

STMs essentially serve the development of management hypotheses, and the success of management interventions and restoration actions can be used to test and revise STMs. This idea requires attention to two model features. First, STMs should contain sufficient detail on management and restoration protocols in the relevant narratives so that they provide a basis for testing and revision. Second, a formal mechanism for the rapid revision of model narratives should be developed, but it does not yet exist. While such a mechanism is being discussed, we encourage model developers to work with managers in designing tests based on the STM. This would create three benefits in addition to maintaining up-to-date models. First, developers will learn whether or not there is sufficient detail in the STM to propose a management action, and therefore whether the STM is complete. Second, the manager would have a clear rationale for the management action and even if the rationale proves incorrect, it will make a valuable contribution to the learning process. Third, the continued interaction between model developers and managers will ensure that STMs continue to be relevant and useful.

\section{References}

1. Westoby, M., B. H. Walker, and I. Noy-Meir. 1989. Opportunistic management for rangelands not at equilibrium. Journal of Range Management 42:266-274. 
2. Bestelmeyer, B. T., J. E. Herrick, J. R. Brown, D. A. Trujillo, and K. M. Havstad. 2004. Land management in the American Southwest: a state-and-transition approach to ecosystem complexity. Environmental Management 34:38-51.

3. Knapp, C. N., and M. Fernandez-Gimenez. 2009. Understanding change: integrating rancher knowledge into state-and-transition models in northwest Colorado. Rangeland Ecology \& Management 62:510-521.

4. Briggs, J. M., A. K. Knapp, J. M. Blair, J. L. Heisler, G. A. Hoch, M. S. Lett, and J. K. McCarron. 2005. An ecosystem in transition: causes and consequences of the conversion of mesic grassland to shrubland. BioScience 55:243-254.

5. Stringham, T. K., W. C. Krueger, and P. L. Shaver. 2003. State and transition modeling: an ecological process approach. Journal of Range Management 56:106-113.

6. Bestelmeyer, B. T., J. R. Brown, K. M. Havstad, G. Chavez, R. Alexander, and J. E. Herrick. 2003. Development and use of state-and-transition models for rangelands. Journal of Range Management 56:114-126.

7. Briske, D. D., S. D. Fuhlendorf, and F. E. Smeins. 2005. State-and-transition models, thresholds, and rangeland health: a synthesis of ecological concepts and perspectives. Rangeland Ecology E Management 58:1-10.

8. Briske, D. D., B. T. Bestelmeyer, T. K. Stringham, and P. L. Shaver. 2008. Recommendations for development of resilience-based state-and-transition models. Rangeland Ecology \& Management 61:359-367.

9. Bestelmeyer, B. T., A. J. Tugel, G. L. Peacock, Jr., D. G. Robinett, P. L. Shaver, J. R. Brown, J. E. Herrick, H. Sanchez, and K. M. Havstad. 2009. State-and-transition models for heterogeneous landscapes: a strategy for development and application. Rangeland Ecology \& Management 62:1-15.

10. Tugel, A. J., J. E. Herrick, J. R. Brown, M. J. Mausbach, W. Puckett, and K. Hipple. 2005. Soil change, soil survey, and natural resources decision making: a blueprint for action. Soil Science Society of America Journal 69:738-747.

11. Pellant, M., P. Shaver, D. Pyke, and J. E. Herrick. 2005. Interpreting indicators of rangeland health, version 4. Denver, CO, USA: Bureau of Land Management Interagency Technical Reference 1734-6. Available at: http://usda-ars.nmsu.edu/ monit_assess/PDF_files/IIRHv4.pdf. Accessed 15 September 2010.

12. Jackson, R. D., And J. W. Bartolome. 2002. A state-transition approach to understanding nonequilibrium plant community dynamics of California grasslands. Plant Ecology 162:49-65.

13. Walker, S., E. Cieraad, A. Monks, L. Burrows, J. Wood, R. Price, G. Rogers, And B. Lee. 2009. Long-term dynamics and rehabilitation of woody ecosystems in dryland South Island, New Zealand. In: R. J. Hobbs and K. N. Suding [eDs.]. New models of ecosystem dynamics and restoration. Covelo, CA, USA: Island Press. p. 78-95.

Authors are Research Ecologist, USDA-Agricultural Research Service Jornada Experimental Range, Las Cruces, NM 88003, USA, bbestelm@nmsu.edu (Bestelmeyer); State Rangeland Ecologist, USDA-Natural Resources Conservation Service (NRCS) California State Office, Davis, CA 95616, USA (Moseley); Rangeland Management Specialist, USDA-NRCS West National Technology Support Center, Portland, OR 97232, USA (Shaver); Rangeland Management Specialist, USDA-NRCS, Central National Technology Support Center, Fort Worth, TX 76115, USA (Sanchez); Professor, Ecosystem Science and Management, Texas A\&M University, College Station, TX 77843, USA (Briske); and Associate Professor, Dept of Forest, Rangeland, and Watershed Stewardship, Colorado State University, Fort Collins, CO 80523, USA. 